American Journal of Immunology 6 (2): 25-28, 2010

ISSN 1553-619X

(C) 2010 Science Publications

\title{
Antiviral and Quantitative Structure Activity Relationship Study for Dihydropyridones Derived from Curcumin
}

\author{
${ }^{1}$ Bahjat A. Saeed, ${ }^{2}$ Kawkab Y. Saour, ${ }^{3}$ Rita S. Elias and ${ }^{4}$ Najim A. Al-Masoudi \\ ${ }^{1}$ Department of Chemistry, College of Education, University of Basrah, Iraq \\ ${ }^{2}$ Department of Pharmaceutical Chemistry, College of Pharmacy, \\ University of Baghdad, Iraq \\ ${ }^{3}$ Department of Pharmaceutical Chemistry, College of Pharmacy, \\ University of Basrah, Iraq \\ ${ }^{4}$ Department of Chemistry, College of Science, University of Basrah, Iraq
}

\begin{abstract}
Problem statement: Pyridones are known to have variety of biological activities like antitumor, antibacterial, anti-inflammatory and antimalarial activities. This study presents antiviral evaluation of dihydropyridones derived from curcumin, as well as curcumin for comparison. Approach: The compounds evaluated for their in vitro antiviral activities against the viruses: HIV-1, Bovin viral Diarrhea, Yellow Fever, Reovirus 1, Herpesvirus 1, Vaccinia, Vescular Stomatitis, Coxackie virus B2, Poliovirus 1 and Respiratory Syncytial viruses by using Microculture Tetrazolium assay (MTT) method. The method was based on the metabolic reduction of 3-(4,5-dimethylthiazol-2yl)-2,5-diphenyltetrazolium bromide. Results: Antiviral biological activities represented as $\mathrm{CC}_{50}$ were within the range $>100-26$ for BHK-21, while they were within the range $>90-\geq 13$ against Respiratory Syncytial Virus when represented as $\mathrm{EC}_{50}$ for example. Both $\mathrm{CC}_{50}$ and $\mathrm{EC}_{50}$ values were found to increase with increasing chain length of the substituent on the nitrogen atom. Conclusion: The in vitro antiviral activities of the tested dihydropyridones can be enhanced by increasing chain length of the substituent on the nitrogen atom.
\end{abstract}

Key words: Dihydropyridones, curcumin, ant-HIV-1, QSAR, logP, AM1 Hamiltonian

\section{INTRODUCTION}

Dihydropyridones are important intermediates for the synthesis of natural products, particularly alkaloids (Dong et al., 2005; Comins and Ollinger, 2001; Elias et al., 2008) and they have been extensively investigated as valuable building block for the construction of piperidines, perhydroquinolens, indolizidines, quinolizidines and other alkaloid systems, with a wide range of a biological and pharmacological activities. These compounds are known for their antiproliferative and antitubolin activities (Magedov et al., 2008) and as potential selective inhibitors of receptor tyrosine kinase (Hu et al., 2008; Goodman et $a l ., 2007)$. Their ability to induce leukaemic cell differentiation has been demonstrated (Pierce et al., 1981). In addition they have potent antimalarial activity (Yeats et al., 2008) and good anticonvulsant activity against acutely elicited Seizures (Revas et al., 2009). On the other hand curcumin is a principal curcuminoid of Indian curry and has known for its antitumor (Ran et al., 2009; Wohlmuth et al., 2010; Ljngman, 2009), antioxidant, anti-inflammatory (Takahashi et al.,
2009; Kuhad et al., 2007; Michaelidou and H-Litina, 2005) and antiarthritic properties (Patil et al., 2009).

Very little was published about the antitumor activities of dihydropyridones and the aim of this study is to investigate the relationship between structure and antitumor activity of a series of dihydropyridones derived from curcumin.

\section{MATERIALS AND METHODS}

The screened dihydropyridones were synthesized via previously described method (Elias et al., 2008). These compounds as well as curcumin were evaluated for preliminary estimation of the in vitro tumor inhibiting activity against a variety of viruses included: HIV-1, Bovin Viral Diarrhea (BVDV), Yellow Fever (YFV), Reovirus 1 (Reo), Herpesvirus 1 (HSV-1), Vaccinia VV), Vescular Stomatitis (VSV), Coxackie virus B2 CVB-2), Poliovirus 1 (Sb-1) and Respiratory Syncytial (RSV) viruses, using microculture assay (MTT) method (Tang et al., 2010). This method is based on the metabolic reduction of 3-(4,5-dimethylthiazol2-yl)-2,5-diphenyltetrazolium bromide (MTT).

istry, College of Education, University of Basrah, Iraq 
Am. J. Immunol., 6 (2): 25-28, 2010

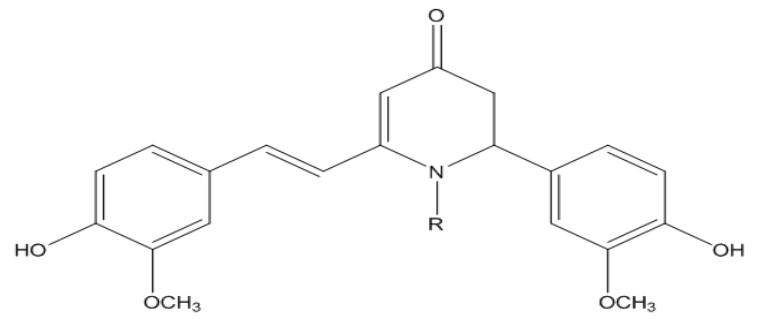

Fig. 1: The structural formula for the studied compounds

Molecular descriptors for the studied compounds, $\log \mathrm{P}$, hydration energy $(\Delta H)$, Refractivity (Ref) and Polaraizability (Pol) were calculated using HyperChem8.5 program, after geometry optimization with the semi empirical RM1 Hamiltonian. The general molecular structure of the studied molecules is shown in Fig. 1.

\section{RESULTS}

The results of the antiviral activities, represented as $\mathrm{CC}_{50}(\mu \mathrm{M})$ and $\mathrm{EC}_{50}(\mu \mathrm{M})$ are summarized in Table 1. The $\mathrm{CC}_{50}$ are within the range $>100-26$ for $\mathrm{BHK}-21$ while $\mathrm{EC}_{50}$ values are within the range $>90-\geq 13$ against Respiratory Syncytial Virus. The calculated molecular descriptors are gathered in Table 2.

The values of $\log P$, Refractivity, Polarizibility increase with increasing molecular weight while hydration energy decreases with increasing molecular weight except for molecule 6.

\section{DISCUSSION}

The tested compounds have variable antiviral activities (both $\mathrm{CC}_{50}$ and $\mathrm{EC}_{50}$ ) with respect to curcumin. In some cases their activity is more than that of curcumin while in others it is less. It is obvious from Table 1 that while the $\mathrm{CC}_{50}$ values of curcumin is less than the majority of the studied compounds for MT-4, MDBK, BHK-21 and Vero-76, the situation is the opposite for compound 5 in the case of BHK-21 and the compounds 4 and 5 in the case of Vero-76. The values of $\mathrm{CC}_{50}$ in these cases are 26, 18 and 13 respectively indicating that the compounds 4 and 5 are more active than curumin. The biological activity expressed as $\mathrm{EC}_{50}$ is in the same direction as could be seen in Table 2. It is worth noting that the $\mathrm{EC}_{50}$ values of compounds 4 and 5 are much smaller than those of curcumin. In both cases the antiviral activity of the studied dihydropyridones increases with increasing chain length of the substituent on the nitrogen atom.
Table 1: Antiviral activities of the studied dihudropyridones represented as $\mathrm{CC}_{50}(\mu \mathrm{M})$

\begin{tabular}{llll}
\hline Comp. & $\mathrm{R}$ & Cell line & $\mathrm{CC}_{50}(\mu \mathrm{M})^{\mathrm{a}}$ \\
\hline 1 & $-\mathrm{CH}_{3}$ & MT-4 $^{\mathrm{b}}$ & $>100$ \\
& & MDBK $^{\mathrm{c}}$ & $>100$ \\
& & BHK-21 & $>100$ \\
& & Vero-76 $^{\mathrm{d}}$ & 90 \\
2 & $-\mathrm{C}_{2} \mathrm{H}_{5}$ & MT4 & \\
& & MDBKc & $>100$
\end{tabular}

$-\mathrm{C}_{3} \mathrm{H}_{7}$

BHK-21

Vero-76 ${ }^{\mathrm{e}} \quad 84$

\section{$\mathrm{MT}^{\mathrm{b}}$}

MDBK

BHK-2 $1^{\mathrm{d}}$

Vero-76 ${ }^{\mathrm{e}}$

MT4 ${ }^{\mathrm{b}}$

$-\mathrm{C}_{4} \mathrm{H}_{9}$

\section{MDBK $^{\mathrm{c}}$}

BHK-21 ${ }^{\mathrm{d}}$

Vero-76 ${ }^{\mathrm{e}}$

MT4 ${ }^{\mathrm{b}}$

5

$-\mathrm{C}_{6} \mathrm{H}_{13}$

\section{MDBK $^{\mathrm{c}}$}

BHK-21

Vero- $76^{\mathrm{e}}$

MT4

6

$-\mathrm{CH}_{2}-\mathrm{Ph}$

MDBK $^{\mathrm{c}}$

BHK-2 $1^{d}$

Vero-76 ${ }^{\mathrm{e}}$

$\mathrm{MT}^{\mathrm{b}}$

MDBK $^{\mathrm{c}}$

BHK- $21^{\mathrm{d}}$

Vero- $76^{\mathrm{e}}$

51

$>100$

$>100$

$>100$

36

36
49

44

18

20

38

26

13
53

$>100$

67

92

Curcumin

${ }^{a}$ Compound concentration required to reduce cell proliferation by $50 \%$ as determined by the MTT method. ${ }^{b}$ Compd. Concn. $(\mu \mathrm{M})$ required to reduce the viability of mock-infected MT-4 $\left(\mathrm{CD}^{+}\right.$Human T-cells Containing an integrated HTLV-1 genome) cells by $50 \%$, as determined by the colorimetric MTT method. ${ }^{\circ}$ Compd. Concn. $(\mu \mathrm{M})$ required to reduce the viability of mock-infected MDBK (Bovine normal kidney) Cells by $50 \%$, as determined by the MTT method. ${ }^{\mathrm{d}}$ Compd. Concn. $(\mu \mathrm{M})$ required to reduce the viability of mock-infected BHK (Hamster normal kidney fibroblast) monolayers by $50 \%$, as determined by the MTT method. ${ }^{~} \mathrm{Compd}$. Concn. $(\mu \mathrm{M})$ required to reduce the viability of mockinfected VERO-76 (Monkey normal kidney) Monolayers by $50 \%$, as determined by the MTT method

Comparison of the activity of compound 1 with 6 shows that the inclusion of a phenyl group in the substituent moiety shifted the threshold of potency from less to more activity in some cases like MT-4, HIV-1, BHK-21, YFV and Reo-1. For substituent longer than propyl group the compounds have activity comparable to that of curcumin and in the case where $\mathrm{R}$ is hexyl group the antiviral activity becomes higher to that of curcumin. Ignoring the data of compound $1 \quad\left(\mathrm{CC}_{50}\right.$ $>100)$ we tried to correlate the activity of the compounds 2-6 represented by $\log \left(1 / \mathrm{CC}_{50}\right)$ against MT-4 with the molecular descriptors, $\log \mathrm{P}$, refractivity, polarizability, hydration energy and carbon number of the substituent $\left(C_{n}\right)$. Very good models with $R^{2}$ values $0.938,0.957,0.968,0.957$ and 0.955 respectively, were obtained when the data of compound 6 are not involved. The models are shown in Eq. 1-5:

$\log \left(1 / \mathrm{CC}_{50}\right)=0.078 \log \mathrm{P}-0.512$ 
Am. J. Immunol., 6 (2): 25-28, 2010

\begin{tabular}{|c|c|c|c|c|c|c|c|c|c|c|c|}
\hline Comp & $\mathrm{R}$ & HIV-1 ${ }^{b}$ & $\mathrm{BDVD}^{\mathrm{c}}$ & $\mathrm{YFV}^{\mathrm{d}}$ & Reo- $1^{\mathrm{e}}$ & $\mathrm{HSV}-1^{\mathrm{f}}$ & $\mathrm{VV}^{\mathrm{g}}$ & $\mathrm{VSV}^{\mathrm{h}}$ & $\mathrm{CVB}^{2} \mathrm{2}^{\mathrm{i}}$ & $\mathrm{Sb}-1^{\mathrm{j}}$ & $\mathrm{RSV}^{\mathrm{k}}$ \\
\hline 1 & $-\mathrm{CH}_{3}$ & $>100$ & $>100$ & $>100$ & $>100$ & $>90$ & $>90$ & $>90$ & $>90$ & $>90$ & $>90$ \\
\hline 2 & $-\mathrm{C}_{2} \mathrm{H}_{5}$ & $>54$ & $>100$ & $>100$ & 68 & $>84$ & $>84$ & $>84$ & $>84$ & $>84$ & $>84$ \\
\hline 3 & $-\mathrm{C}_{3} \mathrm{H}_{7}$ & $>51$ & $>100$ & $>100$ & 50 & $>100$ & $>100$ & $>100$ & $>100$ & $>100$ & $>100$ \\
\hline 4 & $-\mathrm{C}_{4} \mathrm{H}_{9}$ & $>36$ & $>49$ & $>44$ & $>44$ & $>18$ & $>18$ & $>18$ & $>18$ & $>18$ & $>18$ \\
\hline 5 & $-\mathrm{C}_{6} \mathrm{H}_{13}$ & $>20$ & $>38$ & $>26$ & $>26$ & $>13$ & $>13$ & $>13$ & $>13$ & $>13$ & $\geq 13$ \\
\hline 6 & $-\mathrm{CH}_{2}-\mathrm{Ph}$ & $>53$ & $>100$ & $>67$ & $>67$ & $>92$ & $>92$ & $>92$ & $>92$ & $>92$ & $>92$ \\
\hline Curcumin & $>18$ & $>11$ & $>32$ & $>32$ & $>60$ & $>60$ & $>60$ & $>60$ & $>60$ & $>60$ & \\
\hline
\end{tabular}

${ }^{\mathrm{a}}$ Compound Concentration $(\mu \mathrm{M})$ required to achieve $50 \%$ protection. ${ }^{\mathrm{b}}$ Compound Concentration $(\mu \mathrm{M})$ required to achieve $50 \%$ protection of MT- 4 cells from the HIV-1-induced cytopathogenicity, as determined by the MTT method. ${ }^{\circ}$ Compd. Concn. $(\mu \mathrm{M})$ required to achieve $50 \%$ protection of MDBK cells from the BVDV (Bovine Viral Diarrhea Virus)-induced cytopathogenicity, as determined by the MTT method. ${ }^{\mathrm{d} C o m p o u n d}$ concentration $(\mu \mathrm{M})$ required to achieve $50 \%$ protection of BHK (Kidney fibroblast) cells from the YFV (Yellow Fever Virus) and ${ }^{\mathrm{e}}$ Reo (Reovirus1)-induced cytopathogenicity, as determined by the MTT method. ${ }^{\mathrm{f} C o m p d}$. Concn. $(\mu \mathrm{M})$ required to reduce the plaque number of HSV-1 (Herpesvirus 1), ${ }^{\mathrm{g}} \mathrm{VV}$ (Vaccinia Virus), ${ }^{\mathrm{h} V S V}$ (Vesicular Stomatitis Virus), ${ }^{\mathrm{i}} \mathrm{CVB}-2$ (Coxsackie virus B2), ${ }^{\mathrm{j}} \mathrm{Sb}-1$ (Poliovirus 1 ) and ${ }^{\mathrm{k}} \mathrm{RSV}$ ( Respiratory Syncytial Virus) by 50\% in VERO-76 minelayers

Table 3: Calculated molecular descriptors, observed activity against MT-4 and the predicted activity for the stuied dihydropyridones

\begin{tabular}{|c|c|c|c|c|c|c|c|c|}
\hline No & $\log \mathrm{P}$ & Ref. & Pol. & $\Delta \mathrm{H}$ & $\pi$ & $A_{o b s}$ & $A_{\text {pred }}$ & Resdual \\
\hline 2 & 3.29 & 114.03 & 43.11 & -16.69 & 1.02 & -0.238 & -0.251 & -0.013 \\
\hline 3 & 3.67 & 118.56 & 44.64 & -16.28 & 1.55 & -0.232 & -0.210 & -0.013 \\
\hline 4 & 4.16 & 123.16 & 46.78 & -15.85 & 2.13 & -0.192 & -0.184 & 0.008 \\
\hline 5 & 4.95 & 132.36 & 50.45 & -15.01 & 3.10 & -0.114 & -0.121 & -0.007 \\
\hline 6 & 4.72 & 133.90 & 50.93 & -17.76 & 2.01 & -0.237 & -0.237 & 0.000 \\
\hline
\end{tabular}

$\log \left(1 / \mathrm{CC}_{50}\right)=0.007 \operatorname{Ref}-1.064$

$\mathrm{R}^{2}=0.957, \quad \mathrm{~S}^{2}=0.014, \quad \mathrm{~F}=44.3$

$\log \left(1 / \mathrm{CC}_{50}\right)=0.018$ Pol-1.011

$\mathrm{R}^{2}=0.968, \quad \mathrm{~S}^{2}=0.012, \quad \mathrm{~F}=36.3$

$\log \left(1 / \mathrm{CC}_{50}\right)=0.077 \Delta \mathrm{H}+1.047$

$\mathrm{R}^{2}=0.957, \quad \mathrm{~S}^{2}=0.014, \quad \mathrm{~F}=28.4$

$\log \left(1 / \mathrm{CC}_{50}\right)=0.033 \mathrm{Cn}-0.317$

$\mathrm{R}^{2}=0.955, \quad \mathrm{~S}^{2}=0.015, \quad \mathrm{~F}=42.9$

Equations 1-5 indicate a strong dependency of the activity on the alkyl chain length. However, when compound 6 involved in the regression equation poor models with low $\mathrm{R}^{2}$ are predicted for all parameters except for $\Delta \mathrm{H}$. For example, in the case of the model including $\log P$ the correlation coefficient $R^{2}$ is 0.417 , while for $\Delta \mathrm{H}$ as a descriptor, a model with $\mathrm{R}^{2}=0.713$ is obtained. This value became 0.957 when a double parameter regression equation including both $\Delta \mathrm{H}$ and the hydrophobicity constant of the substituent $(\pi)$ was used as shown in Eq. 6:

$\log \left(1 / \mathrm{CC}_{50}\right)=0.134 \Delta \mathrm{H}+2.551 \pi+4.183$

$\mathrm{R}^{2}=0.957, \quad \mathrm{~S}^{2}=0.015, \quad \mathrm{~F}=22.3$

The predicted biological activities for the dihydropyridones from Eq. 6 represented as $\log \left(1 / \mathrm{CC}_{50}\right)$ are shown in Table 3.

\section{CONCLUSION}

This study has shown that the antiviral activity of the studied compounds increases with increasing chain length of the substituent on the nitrogen atom as well the activity could be predicted to good estimate on the basis of a model involving both hydration energy and the hydrophoibicity constant of the substituent.

\section{ACKNOWLEDGEMENT}

The researcher deeply appreciate the kind help of Prof. Paola La Cola and Dr R. Loddo from Department of Biology, University of Cagliari for their kind help in performing the antiviral analyses for the studied compounds.

\section{REFERENCES}

Saeed, B.A. and R.S. Elias, 2010. Density functional theory based quantitative structure activity relationship study of 2,5-bis(1-aziridinyl)-pbenzoquinones with lymphoid leukemia Am. J. Applied Sci., 7: 902-905. DOI: 10.3844/ajassp.2010.902.905.

Dong, D., X. Bi, Q. Liu and F. Cong, 2005. [5C + 1N] Annulation: A novel synthesis strategy of functionalized 2,3-dihydro-4-pyridones. Chem. Commun., 3580-3582. DOI: 10.1039/b505569e

Elias, R.S., B.A. Saeed, K.Y. Saour and N.A. AlMasoudi, 2008. Microwave assisted synthesis of dihydropyridones derived from curcumin. Tet. Lett., 49: 3049-3051. DOI: 10.1016/j.tetlet.2008.03.064 
Goodman, K.B., H. Cui, S.E. Dowdell, D.E. Giatanopoulos and R.L. Ivy et al., 2007. Development of dihydropyridone indazole amides as selective Rhu-kinase inhibitors. J. Med. Chem., 50: 6-9. DOI: 10.21/jm0609014

Hu, E., A. Tasker, R.D. White, R.K. Kunz and J. Hutman et al., 2008. Discovery of aryl aminoquinazoline pyridones as potent, selective and orally efficacious inhibitors of receptor tyrosine kinase c-kit. J. Med. Chem., 51: 30653068. DOI: $10.1021 / \mathrm{jm} 800188 \mathrm{~g}$

Kuhad, A., S. Pilkhwal, S. Sharma, N. Tirkey and K. Chopra, 2007. Effect of curcumin on inflammation and oxidative stress in cisplatininduced experimental nephro toxicity. J. Agric. Food Chem., 55: 10150-10155. DOI: 10.1021/jf0723965

Ljngman, M., 2009. Targeting the DNA damage response in cancer. Chem. Rev., 109: 2929-2950. DOI: $10.1021 / \mathrm{cr} 900047 \mathrm{~g}$

Magedov, I.V., M. Manapadi, M.A. Ogasawara, A.S. Dhwan and S. Rogdi et al., 2008. Strucural simplication of bioactive natural products with multicomponent synthesis. 2. Antiproliferative and antitubulin activities of pyrano[3,2-c]pyridens and pyrano[3,2-c]quinolones. J. Med. Chem., 51: 25612570. DOI: $10.1021 / \mathrm{jm} 701499$ n

Michaelidou, A.S. and D. H-Litina, 2005. Nonsteroidal anti-inflammatory drugs (NSAIDs): A comparative QSAR study. Chem. Rev., 105: 3235-3271. DOI: $10.1021 / \mathrm{cr} 040708 \mathrm{~m}$

Patil, B.S., S.K. Jayaprakasha, K.N.C. Murthy and A. Vikram, 2009. Bioactive compounds: Historical perspectives, opportunities and challenges. J. Agric. Food. Chem., 57: 8142-8160. DOI: 10.1021/jf9000132

Radhi, W.A. and B.A. Saeed, 2010. The investigation of ${ }^{1} \mathrm{~h}$ nmr spectra of 2,3-dihydro-4-pyridinones derived from bisdemethoxycurcumin. Am. J. Applied Sci., 7: 1053-1056. DOI: 10.3844/ajassp.2010.1053.1056.
Ran, C., X. Xu, S.B. Raymond, B.J. Ferrara and K.J. Bacskai et al., 2009. Design, synthesis and testing of difluoroboron-derivatized curcumins as near-infrared probes for in vivo detection of amyloid- $\beta$ deposits. J. Am. Chem. Soc., 131: 15257-15261. DOI: 10.1021/ja9047043

Revas, F.M., J.P. Stables, L. Murphree, R.V. Edwanker and C.R. Edwanker et al., 2009. Antiseizure activity of novel- $\gamma$-aminobutyric acid (A) receptor subtype-selective benzodiazepine analogues in mice and rat models. J. Med. Chem., 52: 17951798. DOI: $10.1021 / \mathrm{jm} 801652 \mathrm{~d}$

Takahashi, M., S. Uechi, K. Takara, Y. Asikin and K. Wada, 2009. Evaluation of an oral carrier system in rats. Bioavailability and antioxidant properties of liposome-encapsulated curcimin. J. Agric. Food Chem., 57: 9141-9146. DOI: 10.1021/jf9013923

Tang, H.F., G. Cheng, J. Wu, X.L. Chen and S.Y. Zhang et al., 2010. Cytotoxic asterosaponins capable of promoting polymerization of tubulin from the starfish Culcita novaeguinea. J. Nat. prod., 72: 284-289. DOI: 10.1021/np8004858

Wohlmuth, H., A.M. Deseo, D.J. Brushett, D.R. Thompson and G. MacFarlane et al., 2010. Diarylheptanoid from Pleuranthodium racemigerum with in vitro postglandin $\mathrm{E}_{2}$ inhibitory and cytotoxic activity. J. Nat. Prod., 73: 743-746. DOI: 10.1021/np900688r

Yeats, C.L., J.F. Betchelor, E.C. Capon, N.J. Cheesman and M. Fry et al., 2008. Synthesis and structureactivity relationship of 4-pyridones as potential antimalarials. J. Med. Chem., 51: 2845-2852. DOI: 10.1021/jm07705790 